\title{
Detection of Human Intestinal Parasites in Commonly Consumed Fresh \\ Leafy Vegetables in Al-Baha Region, Saudi Arabia
}

\section{Eman M Hussein ${ }^{1,4 *}$, Nawal M Osman' ${ }^{2}$, Sarah A Al-Harbi ${ }^{3}$, Ahlam S Al Abbad $^{3}$, Noof A Alghamdi ${ }^{3}$, Raghad A Alghamdi ${ }^{3}$, Lama M Alkhediwi ${ }^{3}$, Safa S Al Zahrani ${ }^{3}$, Yakin H Alhaddad ${ }^{3}$ and Ala A Atta ${ }^{5}$}

${ }^{1}$ Microbiology Department, Faculty of Medicine, Al-Baha University, Al-Baha, KSA

${ }^{2}$ Family Medicine and Community Department, Faculty of Medicine, Al-Baha

University, Al-Baha, KSA

${ }^{3}$ Medical Students, Faculty of Medicine, Al Baha University, Al Baha, KSA

${ }^{4}$ Medical Parasitology, Faculty of Medicine, Suez Canal University, Ismailia, Egypt

${ }^{5}$ Microbiology Department, Faculty of Dentists, Al-Baha University, Al-Baha, KSA

*Corresponding Author: Eman M Hussein, Microbiology Department, Faculty of

Medicine, Al-Baha University, Al-Baha, KSA and Medical Parasitology, Faculty of

Medicine, Suez Canal University, Ismailia, Egypt.
Received: March 23, 2021

Published: May 17, 2021

(C) All rights are reserved by Eman M

Hussein., et al.

\begin{abstract}
Introduction: Ingestion of contaminated fresh leafy vegetables had an important role in the transmission of several intestinal parasitic diseases.

Objectives: This study aimed to identify human intestinal parasites in commonly consumed fresh leafy vegetables in Al-Baha Region, Saudi Arabia.

Methodology: In the current study, 400 leafy vegetable samples collected randomly from the supermarkets and open-aired markets at different times of the year in Al-Baha city were examined to detect the frequency of contamination with human intestinal parasites. Sediments and supernatants of concentrated washing solution of vegetables were examined after stained by iodine and modified Ziehl-Neelsen.

Results: The leafy vegetables contaminated with intestinal parasites were $41 \%$ (164/400). The most contaminated leafy vegetables were spinach, red radish, watercress and lettuce with 58.3\%, 57.5\%, 55\% and 50\%, respectively, while the less contaminated were mint and cabbage with $16.6 \%$ per each. Green onions, parsley, dill, celery, leek and coriander were contaminated with $40 \%$, 37.5\%, $33.3 \%, 31.2 \%, 25 \%$ and $21.9 \%$, respectively. Contaminated leafy vegetables collected from open-air markets was $41 \%$ compared to $33 \%$ of that were collected from supermarkets. These results were statistically significant. About 122 leafy vegetables out of 164 (74.3\%) were contaminated with helminths. Taeniid eggs and Strongyloides larvae were the most common with $18.3 \%$ (30 leafy vegetables per each). About 141 leafy vegetables out of 164 (85.9\%) were contaminated with pathogenic human intestinal protozoa. Cryptosporidium oocysts and Giardia lamblia cysts were the most commonly found with 48 (29.3\%) and 35 (21.3\%), respectively. The highest prevalence was in spring (45.5\%) and the lowest was in summer (33.3\%). These results were statistically significant. Conclusion: Control measures should include treatment of irrigation water, municipal wastewater, treatment of infected persons and mass education of the persons in contact with fresh leafy vegetables to avoid a greater health risk from handling and consuming these vegetables.
\end{abstract}

Keywords: Human Intestinal Parasites; Fresh Leafy Vegetables; Al-Baha Region; Foodborne Disease (FBD) 


\section{Introduction}

Diarrhea is a common clinical manifestation of foodborne disease (FBD) that is an increasing public health problem and responsible for considerable morbidity and mortality globally [13]. Many factors are affecting food safety, such as contamination of water and food, inappropriate storage and food transportation and unhygienic food practices therefore, FBDs are more prevalent in developing countries [4]. Food prepared and consumed at home is a source for a large proportion of foodborne diseases where consumers do not follow proper food handling practices [5-8]. Foodborne illnesses linked to consuming and handling of contaminated fresh vegetables represents one of the major forms of transmitted parasites into the human [9-11]. Vegetables can be contaminated during growth due to sewage sludge, untreated wastewater, contaminated slurry, farm livestock and indigenous [12,13]. Also, wild and domestic animals may be included as sources of contamination [13]. Parasites that are detected in leafy vegetables collected from open-aired markets have a marked difference in prevalence rates when compared with that collected from supermarkets $[13,14]$. The transmission of these parasites to the human occurs through ingestion of the parasite environmental transmission stages such as cyst or oocysts in protozoa and egg and larvae on helminths [14]. In humans, multiple factors are controlling the outcomes of parasitic infection such as the species, genotype of the parasite, infective dose and life stage of the parasite, host immunity, infection site and incubation period [15]. The clinical illness may be mild to severe and manifested within days to weeks, or it may appear as a long-term disease depending on these previous factors [16].

Several surveys from different parts of the world showed that vegetables can be an agent for the transmission of protozoan cysts and oocysts such as Giardia, Cryptosporidium, Entamoeba, Toxoplasma and Cystoisospora. Besides, helminths eggs such as Taeniid, Ascaris, Hymenolepis, Fasciola, Toxocara and larvae of Strongyloides, Trichostrongylus and Hookworms were reported [12-14]. In developing countries, routine diagnosis for monitoring foodborne pathogens is inadequate and nonexistent so, most outbreaks caused by contaminations of fresh leafy vegetables go undetected [16]. In Saudi Arabia, Al-Beinali and his co-workers found that a high rate of parasitic infection among raw vegetables collected from Abhaa province in the southwestern of the kingdom [17]. Whereas Al-Megrin found different rates of intestinal human parasites in raw vegetables collected from the Riyadh sector [18]. The difference in climates in Saudi sectors maybe has an important role in the fre- quencies and types of parasitic contamination of vegetables. Higher rates of contamination were reported in the warm season than those during the cold season and in the dry season than the rainy season $[17,18]$. Al Baha area has different weather characterized by low temperature than other areas in the Saudi Arabia Kingdom [19]. The region of $\mathrm{Al} \mathrm{Baha} \mathrm{is} \mathrm{also} \mathrm{home} \mathrm{to} \mathrm{several} \mathrm{free-range} \mathrm{ani-}$ mals, such as baboons, donkeys, dogs, cats and many birds and rodents. At the same time, it is known for the fertile lands, which are used for the production of may fruits and vegetables [20].

\section{Aim of the Study}

This study aimed to determine the degree of contamination caused by human parasites in commonly used leafy vegetables collected from Al-Baha, Saudi Arabia and its relation to the season.

\section{Materials and Methods}

Description of the study area: Generally, the climate in Al-Baha is mild with temperatures ranging between 12 to $23^{\circ} \mathrm{C}(53.6$ to $\left.73.4^{\circ} \mathrm{F}\right)$. Due to its location at 2,500 meters $(8,200 \mathrm{ft})$ above sea lev$\mathrm{el}, \mathrm{Al}$ Baha's climate is moderate in summer and cold in winter. The area attracts visitors looking for a moderate climate and pristine. Its province is known for forests, wildlife areas, valleys and mountains. Humidity ranges from $52 \%$ - 67\%. While in the mountainous region, which is known as As-Sarah, the weather is cooler in summer and winter. Rainfall in the mountainous region lies in the range of 229 to 581 millimeters ( 9 to 23 in). The average throughout the whole region is 100 to 250 millimeters (3.9 to $9.8 \mathrm{in}$ ) annually [19].

Samples: In the current study, 400 leafy vegetable samples were collected randomly from the supermarkets and open-aired markets from the following: Spinach (50), dill (50), lettuce (40), parsley (40), watercress (40), green onion (40), red radish (40), leek (32), coriander (32), celery (16), cabbage (12) and mint (12). The study was conducted at different times of the year (autumn, winter, spring and summer) in Al-Baha city. The samples were obtained from Al-Baha Open aired markets and supermarkets (200 samples per each). Each fresh sample was put in a separate nylon bag and labeled with a unique number and date of collection. The collection of samples occurred from September 2018 to August 2019. The samples were processed within 1 - 10 hours of collection.

Methods: According to Al-Megrin [16] and Abougrain., et al. [21], a subset from each sample (100 - $150 \mathrm{mg}$ ) was chopped into small pieces and soaked in a plastic bag containing one liter of physi- 
ological saline solution for 15 minutes. Then the plastic bag with vigorous shaking with the aid of a mechanical shaker for 15 minutes. The vegetable sample was removed and the remaining washing solution was left overnight to sediment. Then, the top layer was discarded (approximately $800 \mathrm{ml}$ ) and the remaining wash solution was filtered through a sieve with 425 um pore size to remove large debris and the remainder well transformed to four tubes (each was $50 \mathrm{ml}$ in size) and centrifuged at $2000 \mathrm{~g}$ for min. Following centrifugation, the supernatant was transported into another two test tubes to be floated, separately, by both Zinc sulfate and Sheather's sugar [22]. Then, three drops of floats were examined, one directly, the second was stained with Lugol's iodine and the last drop was stained with modified Ziehl-Neelsen. After the supernatant was removed from the concentrated sample, the sediment was examined under a light microscope with and without staining (Lugol's iodine and modified Ziehl-Neelsen). From each sample, three slides/each tube were prepared for each diagnostic method. Data will be collected and analyzed according to the total prevalence and prevalence/each parasite, prevalence according to the site of sold and according to prevalence seasonal variation.

Statistical analysis

A Chi-square test was used for statistical analysis. The level of significance for $\mathrm{p}$ values was accepted at $\mathrm{p} \leq 0.05$.

\section{Results}

In the present study, the frequencies of contaminated leafy vegetables with human intestinal parasites were 164 out of 400 with $41 \%$ (Table 1). The most contaminated leafy vegetables were spinach, red radish, watercress and lettuce with 58.3\%, 57.5\%, 55\% and $50 \%$, respectively, while the less contaminated were mint and cabbage with $16,6 \%$ per each. Green onions, parsley, dill, celery, leek and coriander were contaminated with $40 \%, 37.5 \%, 33.3 \%, 31.2 \%$, $25 \%$ and $21.9 \%$, respectively. In the current study, the prevalence of parasite contamination among leafy vegetables collected from open-air markets was $41 \%$ compared to $33 \%$ of that collected from supermarkets (Table 2). These results were statistically significant. Regarding to the types of vegetables and markets only spinach and lettuce showed statistically significant.

The distribution of the intestinal parasites, 122 leafy vegetables out of $164(74.3 \%)$ were contaminated with helminths. Taeniid

\begin{tabular}{|c|c|c|c|c|c|}
\hline $\begin{array}{c}\text { Type of exam- } \\
\text { ined vegetables }\end{array}$ & $\begin{array}{c}\text { Number of } \\
\text { examined }\end{array}$ & \multicolumn{2}{|c|}{$\begin{array}{c}\text { Non- } \\
\text { contaminated }\end{array}$} & \multicolumn{2}{c|}{ Contaminated } \\
\cline { 3 - 6 } & & No & $\%$ & No & $\%$ \\
\hline Spinach & 48 & 20 & 41.7 & 28 & 58.3 \\
\hline Dill & 48 & 32 & 66.7 & 16 & 33.3 \\
\hline Lettuce & 40 & 20 & 50 & 20 & 50 \\
\hline Parsley & 40 & 25 & 62.5 & 15 & 37.5 \\
\hline Watercress & 40 & 18 & 45 & 22 & 55 \\
\hline green onion & 40 & 24 & 60 & 16 & 40 \\
\hline Radish & 40 & 17 & 42.5 & 23 & 57.5 \\
\hline Leek & 32 & 24 & 75 & 8 & 25 \\
\hline Coriander & 32 & 25 & 78.1 & 7 & 21.9 \\
\hline Celery & 16 & 11 & 68.8 & 5 & 31.2 \\
\hline Cabbage & 12 & 10 & 83.3 & 2 & 16.6 \\
\hline Mint & 12 & 10 & 83.3 & 2 & 16.6 \\
\hline Total & 400 & 236 & 59 & 164 & 41 \\
\hline
\end{tabular}

Table 1: The contamination percentages of leafy vegetables by enteric human parasitic stages in Al-Baha.

eggs and Strongyloides larvae were the most common parasites with 30 leafy vegetables per each $(18.3 \%)$ and the less frequent were hookworms' eggs with 3 vegetable samples (2.6\%) followed by four samples contaminated with Trichostrongylus larvae (Table 3). Ascaris and Toxocara eggs were detected in $14.6 \%$ and $12.2 \%$ of the contaminated plant, respectively, while Trichuris and H. nana eggs were identified in $3.7 \%$ and $3.1 \%$, respectively. About 141 leafy vegetables out of 164 (85.9\%) were contaminated with human enteric protozoa. Cryptosporidium oocysts and Giardia cysts were the most commonly found with 48 (29.3\%) and 35 (21.3\%) of leafy vegetables and the less frequent were Balantidium coli cysts and Cystoisospora with 2 (1.2\%) and 3 (1.8\%), respectively (Table 4). Cyclospora, Entamoeba, Blastocystis and Toxoplasma oocyst were demonstrated in $15.9 \%, 6.7 \%$., $6.7 \%$ and $3 \%$, respectively.

In the present study, a statistical significant seasonal variation in the relations to the prevalence of parasitic contamination of leafy vegetables was detected whereas the highest rate was found in summer (66.7\%) and lowest one was in winter (20\%). 


\begin{tabular}{|c|c|c|c|c|c|c|c|}
\hline \multirow{2}{*}{$\begin{array}{c}\text { Type of examined } \\
\text { vegetables }\end{array}$} & \multicolumn{2}{|c|}{ Supermarkets } & \multicolumn{2}{c|}{ Open Aired Markets } & \multicolumn{2}{c|}{ Contaminated } & $\begin{array}{c}\text { Chi-square/Fisher exact test } \\
\text { p-value }\end{array}$ \\
\cline { 2 - 7 } & No & $\mathbf{\%}$ & $\mathbf{N o}$ & $\mathbf{\%}$ & $\mathbf{N o}$ & $\mathbf{\%}$ & $.019172^{*}$ \\
\hline Spinach & 10 & 20.8 & 18 & 37.5 & 28 & 58.3 & .220671 \\
\hline Dill & 6 & 12.5 & 10 & 20.8 & 16 & 33.3 & $.011412^{*}$ \\
\hline Lettuce & 6 & 15 & 14 & 35 & 20 & 50 & .743971 \\
\hline Parsley & 8 & 20 & 7 & 17.5 & 15 & 37.5 & .52501 \\
\hline Watercress & 10 & 25 & 12 & 30 & 22 & 55 & .052808 \\
\hline Green onion & 5 & 12.5 & 11 & 27.5 & 16 & 40 & .109769 \\
\hline Red Radish & 9 & 22.5 & 14 & 35 & 23 & 57.5 & 1 \\
\hline Leek & 4 & 20 & 4 & 30 & 8 & 25 & .668929 \\
\hline Coriander & 4 & 12.5 & 3 & 9.4 & 7 & 21.9 & .589639 \\
\hline Celery & 2 & 12.5 & 3 & 18.7 & 5 & 31.2 & 1 \\
\hline Cabbage & 1 & 8.3 & 1 & 8.3 & 2 & 16.6 & 1 \\
\hline Mint & 1 & 8.3 & 1 & 8.3 & 2 & 16.6 & $.001141^{*}$ \\
\hline Total & 66 & 33 & 98 & 49 & 164 & $41 \%$ & \\
\hline
\end{tabular}

Table 2: The contamination percentages of leafy vegetables by enteric parasitic stages of different markets in Al-Baha.

*: The difference is statistically significant.

\begin{tabular}{|c|c|c|c|c|c|c|c|c|c|c|c|c|c|c|c|c|c|c|}
\hline \multirow{2}{*}{$\begin{array}{l}\text { Type of contami- } \\
\text { nated vegetables }\end{array}$} & \multicolumn{2}{|c|}{$\begin{array}{c}\text { Taeniid } \\
\text { eggs }\end{array}$} & \multicolumn{2}{|c|}{$\begin{array}{c}\text { H nana } \\
\text { eggs }\end{array}$} & \multicolumn{2}{|c|}{$\begin{array}{l}\text { Ascaris } \\
\text { eggs }\end{array}$} & \multicolumn{2}{|c|}{$\begin{array}{c}\text { Trichuris } \\
\text { eggs }\end{array}$} & \multicolumn{2}{|c|}{$\begin{array}{c}\text { Toxocara } \\
\text { eggs }\end{array}$} & \multicolumn{2}{|c|}{$\begin{array}{c}\text { Hookworms } \\
\text { eggs }\end{array}$} & \multicolumn{2}{|c|}{\begin{tabular}{|c|}
$\begin{array}{c}\text { Strongyloides } \\
\text { Larvae }\end{array}$ \\
\end{tabular}} & \multicolumn{2}{|c|}{$\begin{array}{c}\text { Trichostrongylus } \\
\text { Larvae }\end{array}$} & \multicolumn{2}{|c|}{ Total } \\
\hline & No & $\%$ & NO & $\%$ & No & $\%$ & No & $\%$ & No & $\%$ & No & $\%$ & No & $\%$ & No & $\%$ & No & $\%$ \\
\hline Spinach 28 & 2 & 7.1 & 0 & 0 & 6 & 21.5 & 0 & 0 & 2 & 7.1 & 0 & 0 & 10 & 35.7 & 0 & 0 & 20 & 71.4 \\
\hline Dill 16 & 2 & 12.2 & 1 & 6.2 & 0 & 0 & 2 & 12.2 & 3 & 18.6 & 1 & 6.2 & 0 & 0 & 1 & 6.2 & 10 & 62.5 \\
\hline Lettuce 20 & 3 & 15 & 1 & 5 & 4 & 20 & 1 & 5 & 1 & 5 & 0 & 0 & 1 & 5 & 1 & 5 & 12 & 60 \\
\hline Parsley 15 & 5 & 33.3 & 1 & 6.7 & 1 & 6.7 & 1 & 6.7 & 2 & 13.3 & 1 & 6.7 & 0 & 0 & 0 & 0 & 11 & 73.4 \\
\hline Watercress 22 & 5 & 22.7 & 1 & 4.8 & 4 & 19.2 & 1 & 4.8 & 2 & 9.6 & 1 & 4.8 & 2 & 9.6 & 0 & 0 & 16 & 72.7 \\
\hline G. Onion 16 & 4 & 25 & 0 & 0 & 2 & 12.5 & 0 & 0 & 3 & 18.6 & 0 & 0 & 3 & 18.6 & 1 & 6.6 & 13 & 81.3 \\
\hline Red Radish 23 & 3 & 13 & 1 & 4.3 & 4 & 17.2 & 0 & 0 & 3 & 13 & 0 & 0 & 7 & 30.6 & 0 & 0 & 18 & 78.2 \\
\hline Leek 8 & 1 & 12.5 & 0 & 0 & 2 & 25 & 0 & 0 & 0 & 0 & 0 & 0 & 2 & 25 & 1 & 12.5 & 6 & 75 \\
\hline Coriander 7 & 2 & 28.6 & 0 & 0 & 0 & 0 & 1 & 14.2 & 2 & 28.6 & 0 & 0 & 2 & 28.6 & 0 & 0 & 7 & 100 \\
\hline Celery 5 & 1 & 20 & 0 & 0 & 1 & 20 & 0 & 0 & 0 & 0 & 0 & 0 & 3 & 60 & 0 & 0 & 5 & 100 \\
\hline Cabbage 2 & 1 & 50 & 0 & 0 & 0 & 0 & 0 & 0 & 1 & 50 & 0 & 0 & 0 & 0 & 0 & 0 & 2 & 100 \\
\hline Mint 2 & 1 & 50 & 0 & 0 & 0 & 20 & 0 & 0 & 1 & 50 & 0 & 0 & 0 & 0 & 0 & 0 & 2 & 100 \\
\hline Total & 30 & 18.3 & 5 & 3.1 & 24 & 14.6 & 6 & 3.7 & 20 & 12.2 & 3 & 1.8 & 30 & 18.3 & 4 & 2.4 & 122 & 74.4 \\
\hline
\end{tabular}

Table 3: Distribution of the pathogenic intestinal helminths among leafy vegetables collected from in Al-Baha. 


\begin{tabular}{|c|c|c|c|c|c|c|c|c|c|c|c|c|c|c|c|c|c|c|}
\hline \multirow{2}{*}{\begin{tabular}{|c|} 
Type and numbers \\
of contaminated \\
vegetables
\end{tabular}} & \multicolumn{4}{|c|}{\begin{tabular}{|c|c|}
$\begin{array}{c}\text { Entamoeba } \\
\text { cyst }\end{array}$ & $\begin{array}{c}\text { ciardia } \\
\text { cyst }\end{array}$ \\
\end{tabular}} & \multicolumn{2}{|c|}{$\begin{array}{c}\text { Balantidium } \\
\text { cyst }\end{array}$} & \multicolumn{4}{|c|}{ 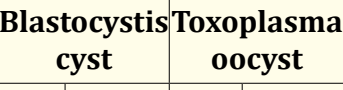 } & \multicolumn{2}{|c|}{$\begin{array}{c}\text { Cryptosporidiun } \\
\text { oocyst }\end{array}$} & \multicolumn{2}{|c|}{$\begin{array}{c}\text { Cyclospora } \\
\text { oocyst }\end{array}$} & \multicolumn{2}{|c|}{$\begin{array}{c}\text { Cystoisospora } \\
\text { oocysts }\end{array}$} & \multicolumn{2}{|c|}{ Total } \\
\hline & No & $\%$ & No & $\%$ & No & $\%$ & No & $\%$ & No & $\%$ & No & $\%$ & No & $\%$ & No & $\%$ & No & $\%$ \\
\hline Spinach & 2 & 7.1 & 2 & 7.1 & 1 & 3.6 & 2 & 7.1 & 1 & 3.6 & 10 & 35.7 & 4 & 14.4 & 0 & 0 & 22 & 78.6 \\
\hline Dill & 2 & 12.6 & 2 & 12.6 & 0 & 0 & 2 & 12.6 & 1 & 6.3 & 3 & 18.8 & 2 & 12.6 & 1 & 6.3 & 15 & 93.8 \\
\hline Lettuce & 0 & 0 & 2 & 10 & 0 & 0 & 0 & 0 & 0 & 0 & 4 & 20 & 10 & 50 & 0 & 0 & 16 & 80 \\
\hline Parsley & 0 & 0 & 4 & 26.7 & 0 & 0 & 1 & 6.6 & 0 & 0 & 4 & 26.7 & 4 & 26.7 & 1 & 6.6 & 14 & 93.3 \\
\hline Watercress & 2 & 9 & 6 & 27 & 0 & 0 & 1 & 4.5 & 1 & 4.5 & 8 & 36 & 2 & 9 & 0 & 0 & 20 & 91 \\
\hline Green Onion & 1 & 6.3 & 5 & 31.1 & 1 & 6.3 & 1 & 6.3 & 1 & 6.3 & 4 & 25 & 0 & 0 & 0 & 0 & 13 & 81.3 \\
\hline Red Radish & 3 & 13 & 4 & 17.4 & 0 & 0 & 2 & 8.8 & 0 & 0 & 9 & 39.3 & 1 & 4.4 & 0 & 0 & 19 & 73.9 \\
\hline Leek & 0 & 0 & 3 & 37.5 & 0 & 0 & 1 & 12.5 & 0 & 0 & 4 & 50 & 0 & 0 & 0 & 0 & 8 & 100 \\
\hline Coriander & 0 & 0 & 6 & 85.7 & 0 & 0 & 1 & 14.3 & 0 & 0 & 0 & 0 & 0 & 0 & 0 & 0 & 7 & 100 \\
\hline Celery & 1 & 20 & 0 & 0 & 0 & 0 & 0 & 0 & 0 & 0 & 0 & 0 & 3 & 60 & 1 & 20 & 5 & 100 \\
\hline Cabbage & 0 & 0 & 1 & 50 & 0 & 0 & 0 & 0 & 0 & 0 & 1 & 50 & 0 & 0 & 0 & 0 & 2 & 100 \\
\hline Mint & 0 & 0 & 0 & 0 & 0 & 0 & 0 & 0 & 1 & 50 & 1 & 50 & 0 & 0 & 0 & 0 & 2 & 100 \\
\hline Total & 11 & 6.7 & 35 & 21.3 & 2 & 1.2 & 11 & 6.7 & 5 & 3.0 & 48 & 29.3 & 26 & 15.9 & 3 & 1.8 & & 85.9 \\
\hline
\end{tabular}

Table 4: Distribution of the pathogenic human intestinal protozoa among leafy vegetables collected from in Al-Baha.

\begin{tabular}{|c|c|c|c|c|c|c|c|}
\hline \multirow{2}{*}{ Seasons } & \multicolumn{2}{|c|}{ Contaminated } & \multicolumn{2}{|c|}{ Not-Contaminated } & \multicolumn{2}{c|}{ Total } & \multirow{2}{*}{ p-value } \\
\cline { 2 - 7 } & $\mathbf{N o}$ & $\mathbf{\%}$ & $\mathbf{N o}$ & $\mathbf{\%}$ & No & $\mathbf{\%}$ & \\
\hline Autumn & 44 & 44 & 56 & 56 & 100 & 100 & \multirow{2}{*}{.00001} \\
\hline Winter & 20 & 20 & 80 & 80 & 100 & 100 & \\
\hline Spring & 40 & 36.4 & 70 & 63.6 & 110 & 100 & \\
\cline { 1 - 7 } Summer & 60 & 66.7 & 30 & 33.3 & 90 & 100 & \\
\hline Total & 164 & 41 & 236 & 59 & 400 & 100 & \\
\hline
\end{tabular}

Table 5: The frequency of Contaminated leafy vegetables compared to not-contaminated with the seasonal distribution.

The result is statistically significant.

\section{Discussion}

The force of habits of eating fresh leafy vegetables particularly as an essential component of salad plays a critical epidemiologic role in transmitting parasitic food-borne diseases in the presence of the infective stages through handling and consuming [14].

Results from this study demonstrated that $41 \%$ of the fresh leafy vegetables collected from Al-Baha were contaminate with human enteric parasites (Table 1). Similar reports demonstrated the frequency of parasitic contamination in some parts of Saudi Arabia but notably it was high in our study. In agreement with our results, Gabber and Shaker estimated an overall prevalence rate of $46 \%$ (184 out 400) of parasitic contamination among eight leafy veg- etables in Tabuk [23]. Also, Albeinali and his co-workers found that a high rate of parasitic infection among 5 raw vegetables collected from the central vegetable market in Abhaa city in the southwestern of the kingdom with $27.2 \%$ [17]. In controversy, a low prevalence was reported on Riyadh that only 76 out of 470 samples (16\%) were contained parasite stages [18]. In Al Qassim, the prevalence rate ranged from $23.8 \%$ to $36.9 \%$ for contaminated with human intestinal helminths and protozoa [24]. When raw vegetables collected from cities of the Sarawat Mountain of Saudi Arabia including lettuce, green onions, cucumbers, carrots, spinach, tomatoes, parsley, ginger, radish and arugula were examined to identifying the frequency of parasitic contamination the rates were $19 \%$ (38/200) in Albaha, followed by 15\% (30/200) in Baljurish, 12.5\% 
(25/200) in Altaif and 11\% (22/200) in Abha [19]. Globally regarding some developing countries, the prevalence of contamination was high in Kenya and in Libya with $75.6 \%$ and 58\%, respectively while it was lower than our results with $31.7 \%$ and 29\% in Egypt and Iraq, respectively [25-28]. Therefore, the difference between our study results and the other study were referred to the weather variability, types of vegetables, sample size/each, seasons of collection, vegetable and the methods used in the examination.

In the current study, the prevalence of parasite contamination among leafy vegetables collected from open-air markets were $41 \%$ compared to $33 \%$ of that collected from supermarkets. These results were statistically significant although no statistically significant results were detected per certain type of vegetable particularly. In agreement with our results intestinal human parasites that are detected in leafy vegetables collected from open-aired markets have a marked difference in prevalence rates when compared with that collected from supermarkets $[13,14]$. This may be referred to the degrees of contamination through handling the vegetables that are less in the supermarket than in open-aired markets. The most contaminated leafy vegetables in our study were spinach and red radish with $60 \%$ and $59.3 \%$, respectively, while the less contaminated were mint and cabbage with $14.3 \%$ and $15 \%$, respectively (Table 2). Green onions and Coriander were contaminated with $41.2 \%$ each. Parsley, leek and lettuce were contaminated by $40 \%$ each. Watercress and dill were contaminated by $37.5 \%$ and $36 \%$, respectively. Al Megrin demonstrated that the rates of parasitic contaminations were $27.8 \%$ (17/61) in lettuce, $22.8 \%(13 / 57)$ in watercress, $20.6 \%(7 / 34)$ in leek, $19.1 \%(9 / 47)$ in green onion, $17.4 \%$ (15/87) in paisley, $15.4 \%(4 / 26)$ in spinach, $13.6 \%(3 / 22)$ in basil, $11.5 \%(3 / 26)$ in coriander, $9.4 \%(3 / 32)$ in radish, 5.3\% $(1 / 19)$ in dill and $4.7 \%(2 / 42)$ in mint. No parasites were detected in 17 samples collected from cabbage [18]. Albinali., et al. found that in descending order $28 \%$ of green onion, $25 \%$ of reddish, $17 \%$ of watercress, $17 \%$ lettuce and $13 \%$ of leek were contaminated [17]. The prevalence in Tabuk was $15.76 \%$ in cabbage and $14.13 \%$ in watercress, $13.04 \%$ in lettuce and $8.7 \%$ in green onion [23]. In others developing countries such as Egypt they supported our results as the high rate of contamination varies according to the shape and surface of vegetables whereas watercress, lettuce and parsley were the most contaminate [28,29]. Also, lettuce and water cress were contaminating significantly than other vegetables in Libya [25]. The variability in frequencies may be related to the number and type of examined vegetables as previously mentioned in the study of Alqumber [19] who demonstrated that the highest contamination was observed in radishes, parsley, carrots, spinach and ginger while the lowest contamination was detected in cucumbers, tomatoes and green onions. Furthermore, in a study was done in Riyadh, women were at risk of improper food -holding temperature with $45.28 \%$, cross contaminations were $32.23 \%$ and food from unsafe sources was $22.39 \%$ [30]. In additions, some vegetables are highly susceptible to infection through post harvesting handing methods such as spinach and red radish which are the most contaminated vegetable in our study.

Regarding the distribution of the intestinal parasitic helminths among leafy vegetables collected from in Al-Baha, 122 leafy vegetables out of 164 (74.3\%) were contaminated with helminths. In the present study, Taeniid eggs detected in $18.3 \%$ of leafy vegetables that may be belonged to Echinococcus granulosus, Taenia spp. and Multiceps multiceps. They cause hydatidosis, coenouris and neurocysticercosis (Taenia solium infection) that were showed in KSA previously [17]. A high frequency of Taeniid eggs was coordinated with a study done in Riyadh with a prevalence rate of $19.7 \%$ [18]. In contrast, low prevalence's were showed in al-Qassim and Tabuk with $10 \%$ and $4.35 \%$, respectively [23,24]. Also, no Taeniid eggs were recorded in Abha [17]. The zoonotic transmission of Taeniid may have a role in the high rate in our study. These can be explained in the case of Taenia solium as it should be of human origin where many of the expertise are non-Muslims. Also, Strongyloides larvae were detected in $18.3 \%$ of contaminated leafy vegetables in the present study. In agreement with our results, Omar., et al. demonstrated a 15\% contamination of leafy vegetables collected from Hail [31]. Low prevalence was showed in Tabuk with $9.24 \%$ [23]. The contamination by this parasite was zero among leafy vegetables collected from both Al-Qassim, Riyadh and Abha $[17,18,24]$. Although Strongyloides infection in human span from asymptomatic light infections to chronic symptomatic but hyperinfection syndrome and a potentially fatal spread of the larvae in immunocompromised patients could lead to $85 \%$ mortality rate [32]. In the current study, Ascaris and Toxocara eggs were detected in $14.6 \%$ and $12.2 \%$ of the contaminated plant, respectively, while Trichuris and $H$. nana eggs were identified in $3.7 \%$ and $3.1 \%$ respectively. The less frequent were hookworms' eggs with 1.8\% and Trichostrongylus larvae (2.6\%). In agreement with our data Albainali., et al. demonstrated that Ascaris lumbricoides was detected with $15.8 \%$ while in contrast to our results Ancylostoma duodenale was 19\% [17]. Moreover, Ascaris demonstrated with 
$21.74 \%$ in Tabuk. In contrast in Riyadh spp of Ascaris, Hymenolepis and Ancylostoma was demonstrated in high prevalence rates than our study with $26.3 \%, 14.5 \%$ and $11.8 \%$, respectively, while in the case of Trichostrongylus (2.6\%) the rate is similar to our result [18]. In another study, Trichuris trichiura and Trichostrongylus were the most commonly detected infectious agents in the raw vegetables, while Hymenolepis nana was the least prevalent [19]. The zoonotic transmission particularly from stray cats, dogs and primates maybe play a role in the high prevalence of helminths eggs in our study.

In the present study, the distribution of the intestinal parasitic protozoa 41 leafy vegetables out of 164 (85.9\%) was contaminated. Cryptosporidium oocysts and Giardia cysts were the most commonly found with 48 (29.3\%) and 35 (21.3\%) leafy vegetables and the less frequent were Balantidium coli cysts and isopora oocysts with $1.2 \%$ and $1.8 \%$, respectively (Table 4). Cyclospora oocysts, Entamoeba cysts, Blastocystis cysts and Toxoplasma oocysts were demonstrated in $15.9 \%, 6.7 \%$., $6.7 \%$ and $3 \%$, respectively. In agreement with the current study results, Al-Migrin showed that Giardia lamblia, Blastocystis and Toxoplasma gondii were detected in $31.6 \%, 17.1 \%$ and 6.6\%, respectively [18]. Besides, Entamoeba $s p$ was the common protozoa in contaminated vegetables collected from Tabuk while Giardia was only showed in 2.17\% [23]. Our results were in controversy with Albainali., et al. who demonstrated that Blastocystis (12.6\%) were the most common isolated protozoa [17]. In Al-Qassim, Giardia were 20.7\%, Cryptosporidium were $13 \%$, Entamoeba were $10.7 \%$ and Balantidium coli were $2.3 \%$ [22]. In the other side, no protozoa were detected in the study of Alqumber [19]. This variability may be related to the role of zoonotic contamination as there are many domestic and wild animals present in Al-Bahaa. In addition, Cryptosporidium oocysts had the ability to strongly adhering to spinach and were internalized by the leaves therefore it was the most detected parasites in some studies [29]. In Spain 12 out of 19 (63.2\%) samples of green vegetables used in salads products were contaminated with cryptosporidium only [32]. However, Giardia is the most prevalent parasite in contaminated leafy vegetables in another study [30]. The use of sewage water for irrigation is a common way of these parasitic contaminations. For Cryptosporidium Spp. and Giardia lamblia, a large range of hosts may be infected with shedding oocysts/cysts in their faeces that can resist the variabilities in weather easily $[33,34]$. Dose-response modelling predicts a probability of human infection following ingestion of a single oocyst of Cryptosporidium could be as high as $72 \%$ [35] while the minimal infective dose of Giardia is less than 10 cysts [34].
Regarding seasonal variation, the present study results indicated a statistically significant seasonal variation, with high rate in summer (66.7\%) followed in autumn (44\%), springer $(36.4 \%)$ and winter (20\%). Our results are consistent with previous studies that reported higher rates of parasitic contamination in vegetables during warm seasons than cold talking in consideration weather of summer in Al-Baha likes weather of springer in other areas. In contrast, the parasites were more common from September to December (autumn) in Abha [17]. In the study of Riyadh, the highest prevalence was showed in spring (23.1\%), followed in descending order by summer (17.9\%), autumn (10.6\%) and winter (9.9\%) [18]. These can be explained by the excretion of parasites resistance stages from human or animals to the environment are more common in warm weather than cold [25]. Also, post-harvest fecal contamination of vegetables may occur during handling and transport of vegetables and this may occur during splashing the vegetables with contaminated water or unhygienic hands to keep them fresh and by this way the parasite transmission to the human becomes easy [25]. In Egypt the rate of parasitic contamination in vegetable samples was the highest in summer (49\%) and the lowest was in winter (10.8\%) [29]. The excretion of parasite's eggs to environment by human or animals is high in warm seasons compared to cold seasons [37]. Another study in Hanoi, Vietnam, showed that the number of eggs recovered from vegetables was higher in the dry season (78\%) than in the rainy season (22\%) and it is assumed that eggs on the surface of vegetables are washed away by rain [38].

The high level of vegetable contamination with parasitic stages in this study is significant hence control measures should include treatment of irrigation water, municipal wastewater before use, treatment of infected persons and mass education of the populace on the danger of eating inadequately washed or raw vegetables. Provision of a good sanitary system in rural and urban areas should be adopted.

\section{Conclusion}

Control measures should include treatment of irrigation water, municipal wastewater, treatment of infected persons and mass education of the persons in contact with fresh leafy vegetables to avoid a greater health risk from handling and consuming these vegetables. 


\section{Conflict of Interests}

The authors declare that there is no conflict of interests regarding the publication of this paper.

Funding

None.

\section{Bibliography}

1. Fleury MD., et al. "A descriptive analysis of hospitalization due to acute gastrointestinal illness in Canada, 1995 -2004". Canadian Journal of Public Health 99 (2008): 489-493.

2. WHO "First Formal Meeting of the Foodborne Disease Burden Epidemiology Reference Group (FERG)” 26-28 (2007).

3. Helms M., et al. "Short and long term mortality associated with foodborne bacterial gastrointestinal infections: registry-based study". British Medical Journal 326 (2003): 357.

4. Jay LS., et al. "A video study of Australian domestic food-handling practices". Journal of Food Protection 62 (2016): 921-928.

5. Finley R., et al. "High-risk food consumption and food safety practices in a Canadian community". Journal of Food Protection 72 (2009): 2575-2586.

6. Redmond EC and Griffith CJ. "Consumer food handling in the home: a review of food safety studies". Journal of Food Protection 66 (2003): 130-161.

7. Redmond EC., et al. "Microbiological and observational analysis of cross-contamination risks during domestic food preparation". British Food Journal 106 (2004): 581-597.

8. Kang GM., et al. "Prevalence of intestinal parasites in rural Southern Indians". Tropical Medicine and International Health 3 (1998): 70.

9. WHO: Schistosomiasis and soil-transmitted helminth infections. Fifty-Fourth World Health Assembly. Volume WHA54.19 (2001).

10. Vuong TA., et al. "Fecal and protozoan parasite contamination of water spinach (Ipomoea aquatic) cultivated in urban wastewater in Phnom Penh, Cambodia". Tropical Medicine and International Health 12 (2007): 73-81.
11. De Oliveira CA and PM Germano. "Presence of intestinal parasites in vegetables sold in the metropolitan area of Sao Paulo-SP, Brazil II-Research on intestinal protozoans". Revista de Saúde Pública 26 (1992): 332-335.

12. Dawson D. "Foodborne protozoan parasites". International Journal of Food Microbiology 103.2 (2005): 207-227.

13. Duedu 0., et al. "A comparative study of the prevalence of human parasites found in fresh vegetables sold in supermarkets and open-aired market in Accra, Ghana". BMC Research Notes 7 (2014): 836.

14. Al- Mohamed M., et al. "Parasitic contamination of fresh vegetables sold at central market in Khartoum state, Sudan". Annals of Clinical Microbiology and Antimicrobials 15 (2016): 17.

15. Cable J., et al. "Global change, parasite transmission, and disease control: lessons from ecology". Philosophical Transactions of the Royal Society B: Biological Sciences 372.1719 (2017): 20160088.

16. Hoberg EP and Brooks DR. "Evolution in action: climate change, biodiversity dynamics and emerging infectious disease". Philosophical Transactions of the Royal Society B: Biological Sciences 370.1665 (2015): 20130553.

17. Albinali AM. "The prevalence of parasites in commonly used leafy vegetables in southwestern, Saudi Arabia". Saudi Medical Journal 27 (2006): 613-616.

18. Al-Megrin W. "Prevalence of intestinal parasites in leafy vegetables in Riyadh, Saudi Arabia". International Journal of Zoological Research 6.3 (2010): 190-195.

19. Climate data of Saudi Arabia Jeddah Regional Climate Center. "Archived from the original on 2012-05-12". (2016).

20. Alqumber MA. "Parasitic Contamination in Raw Vegetables in Cities of the Sarawat Mountain Range of Saudi Arabia". Life Science Journal 11 (2014): 9.

21. Abougrains AK., et al. "Parasitological contamination in salad vegetables in Tripoli-Libya”. Food Control 21.5 (2010): 760762. 
22. Garcia L. "Macroscopic and microscopic examination of fecal specimen". In diagnostic medical parasitology, 5th ed. ASM Press, Washington, DC (2007): 732-830.

23. Gabber R and Shaker A. "Prevalence of some human enteroparasites in commonly consumed raw vegetables in Tabuk Saudi Arabia". Journal of Food Protection 79.4 (2014): 655-658.

24. Ammar A and Omar H. "The prevalence of leafy vegetableborne parasites in Al-Qassim region Saudi Arabia". Journal of Agriculture and Veterinary Sciences. Al Qassim University 6 (2013): 29-40.

25. Abougrain AK., et al. "Parasitological contamination in salad vegetables in Tripoli-Libya”. Food Control 21.5 (2010): 57605762.

26. Hadi AM. "Isolation and identification of intestinal parasites from vegetables from different markets of Iraq". Bulletin of the Iraq Natural History Museum 11.4 (2011): 17-25.

27. Nyarango RM., et al. "The risk of pathogenic intestinal parasite infections in Kisii Municipality, Kenya". BMC Public Health 8.1 (2008): 237.

28. Said DE. "Detection of parasites in commonly consumed raw vegetables”. Alexandria Journal of Medicine 48 (2012): 345352.

29. Eraky MA., et al. "Parasitic Contamination of Commonly Consumed Fresh Leafy Vegetables in Benha, Egypt". Journal of Parasitology Research 14 (2014).

30. Alsayeqh AF. "Foodborne disease risk factor among women in Riyadh, Saudi Arabia". Food Control. 50 (2015): 85-91.

31. Omar Amer., et al. "Strongyloides stercoralis in leafy vegetables, humans, and cats as a possible source for zoonotic disease in Hail, Saudi Arabia". International Journal of Medicine in Developing Countries 3.6 (2019): 553-556.

32. Mejia R., et al. "Screening prevention, and treatment of hyperinfection syndrome and disseminated infections caused by Strongyloides stercoralis". Current Opinion in Infectious Diseases - LWW Journals 25 (2012): 458-463.
33. Macarisin D., et al. "Leaf Stomata Harboring Cryptosporidium parvum Oocysts: a Potential Threat to Food Safety". Applied and Environmental Microbiology 76.2 (2010): 555-559.

34. Bidya Prasad., et al. "A method for incorporating a time-doseresponse model into a Giardia lamblia outbreak". Journal of Water and Health 1. 15.4 (2017): 490-504.

35. Messner M and Berger P. "Cryptosporidium infection risk result of new dose-response modeling”. Risk Analysis 36 (2016): 1969-1982.

36. Uga S., et al. "Parasite egg contamination of vegetables from a suburban market in Hanoi, Vietnam". Nepal Medical College Journal 11.2 (2009): 75-78.

37. Adanir R and. Tasci F. "Prevalence of helminth eggs in raw vegetables consumed in Burdur, Turkey". Food Control 31.2 (2013): 482-484.

38. Eslami A., et al. "Study on the prevalence seasonal incidence and economic importance of parasitic infections of small ruminants in the province of Semnan". Pajouhesh Sazandegi 58 (2003): 55-58.

\section{Volume 4 Issue 6 June 2021}

(C) All rights are reserved by Eman M Hussein., et al. 